Supporting Information

Dust-Catalyzed Oxidative Polymerization of Catechol and its Impacts on Ice Nucleation Efficiency and Optical Properties

Nicole Link, ${ }^{\ddagger}$ Nicole Removski,,${ }^{\ddagger}$ ingwei Yun, ${ }^{\ddagger}$ Lauren T. Fleming, ${ }^{\xi}$ Sergey A.

Nizkorodov, ${ }^{\xi}$ Allan K. Bertram ${ }^{\ddagger}$ and Hind A. Al-Abadleh*\$

Department of Chemistry, University of British Columbia, 2036 Main Mall, Vancouver, BC, V6T 1Z1, Canada

'Department of Chemistry, University of California, Irvine, California 92697, United States

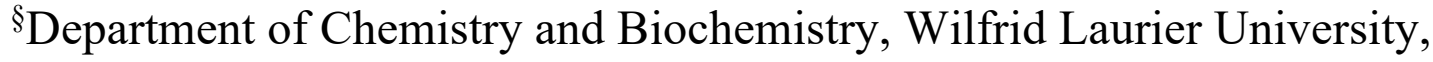
Waterloo, ON, N2L 3C5, Canada

Journal: ACS Earth and Space Chemistry

Prepared: June 4, 2020

Supplementary Data (9 pages)

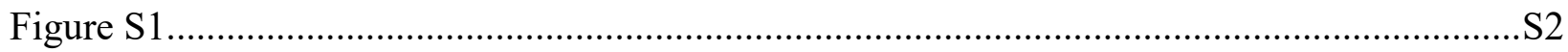

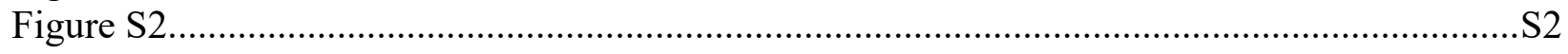

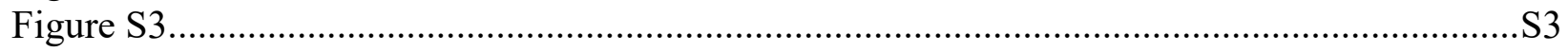

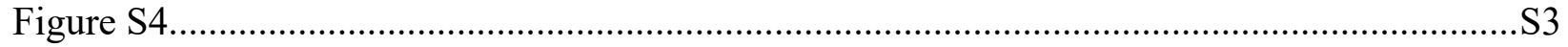

Figure S5

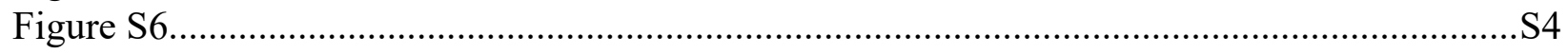

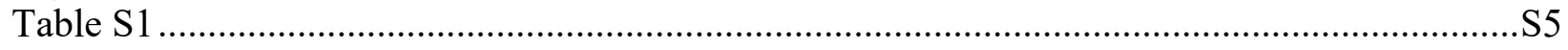

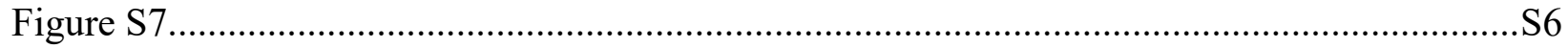

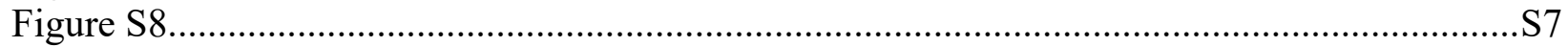

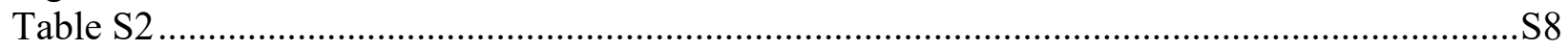

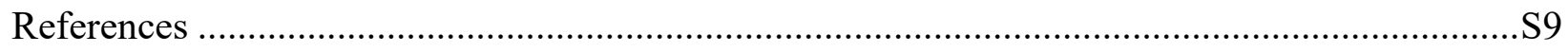




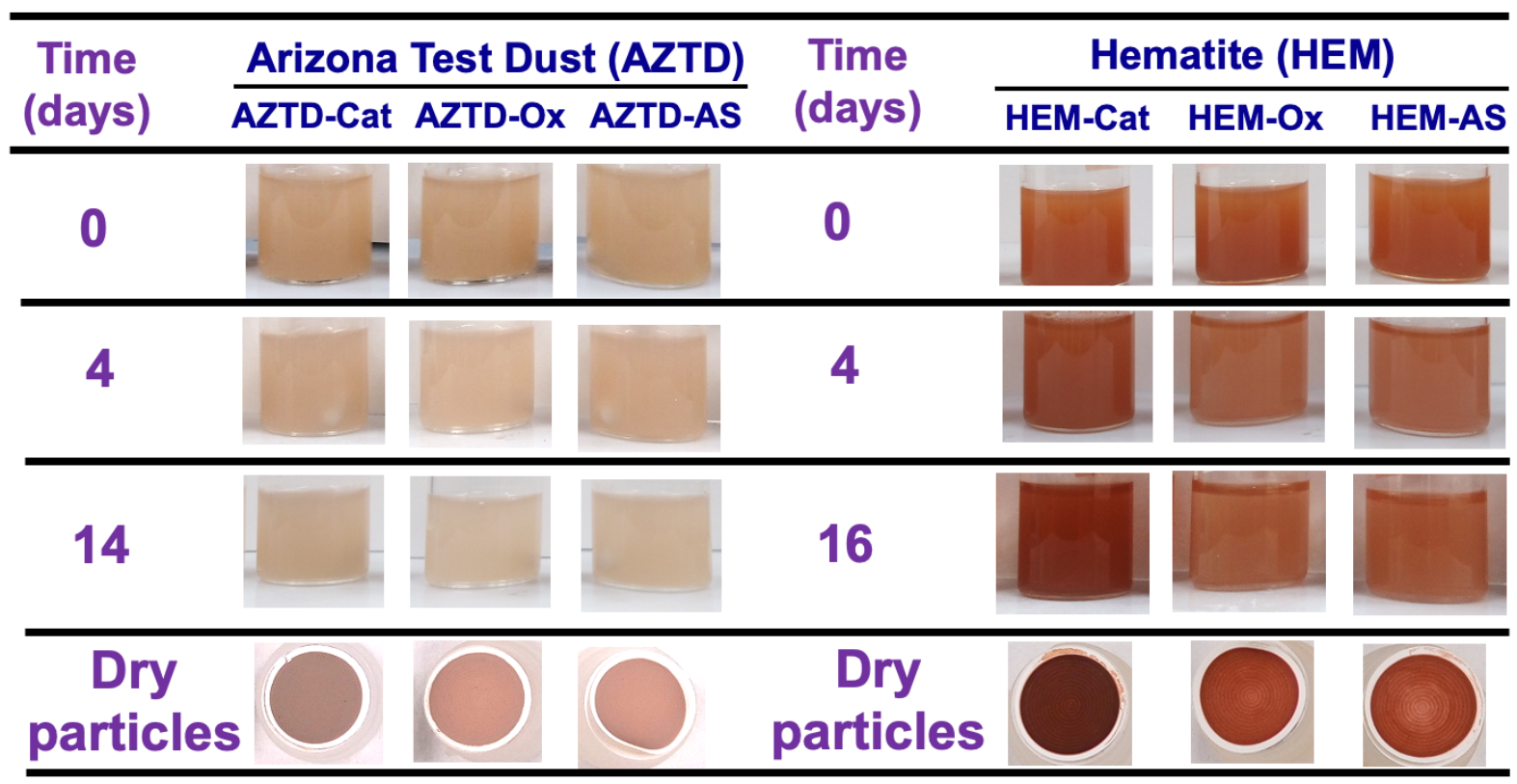

Figure S1. Selected photos of AZTD $\left(1 \mathrm{~g} \mathrm{~L}^{-1}\right)$ and hematite $\left(0.3 \mathrm{~g} \mathrm{~L}^{-1}\right)$ slurries as a function of reaction time with catechol (Cat), oxalic acid (Ox) and ammonium sulfate (AS) at pH 1 in the dark. Concentration of ligands in the dust slurries is $1 \mathrm{mM}$ and in the hematite slurries is $100 \mu \mathrm{M}$. Also shown are filters loaded with the dry particles.

\begin{tabular}{|c|c|c|c|c|c|}
\hline \multirow{2}{*}{$\begin{array}{l}\text { Time } \\
\text { (days) }\end{array}$} & \multicolumn{2}{|c|}{ Arizona Test Dust (AZTD) } & \multirow{2}{*}{$\begin{array}{c}\text { Time } \\
\text { (days) }\end{array}$} & \multicolumn{2}{|c|}{ Hematite (HEM) } \\
\hline & AZTD-Ox-Cat & AZTD-AS-Cat & & HEM-Ox-Cat & HEM-AS-Cat \\
\hline 0 & & & 0 & & \\
\hline 4 & & & 4 & & \\
\hline 14 & & & 16 & & \\
\hline $\begin{array}{r}\text { Dry } \\
\text { partic }\end{array}$ & & & $\begin{array}{l}\text { Dry } \\
\text { articl }\end{array}$ & & \\
\hline
\end{tabular}

Figure S2. Selected photos of ATD $\left(1 \mathrm{~g} \mathrm{~L}^{-\mathbf{1}}\right)$ and hematite $\left(0.3 \mathrm{~g} \mathrm{~L}^{-\mathbf{1}}\right)$ slurries as a function of reaction time in solutions containing catechol (Cat)/oxalic acid (Ox), and Cat/ammonium sulfate (AS) at $\mathrm{pH} 1$ in the dark. Concentration of ligands in the dust slurries is $1 \mathrm{mM}$ and in the hematite slurries is $100 \mu \mathrm{M}$. Also shown are filters containing the dry particles. 
(a)

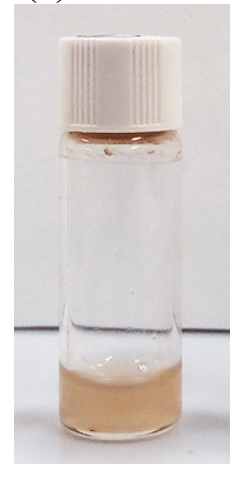

(b)

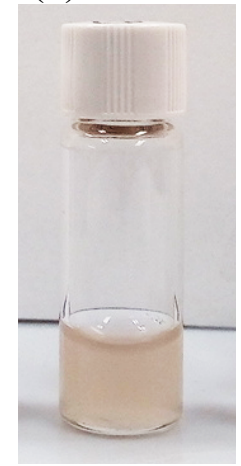

(c)

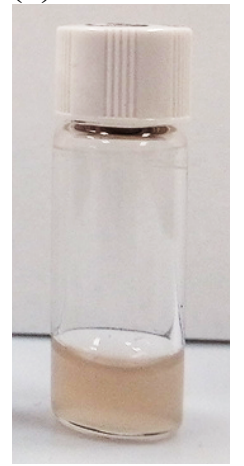

(d)

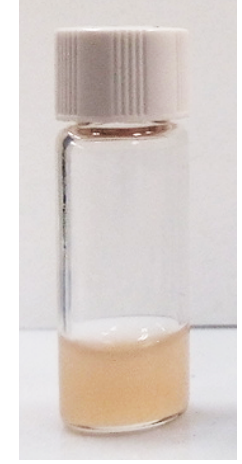

Figure S3. AZTD slurries at $\mathrm{pH} 1$ containing (left to right): (a) Cat, (b) Cat and Ox, (c) Cat and AS, and (d) no Cat or Ox or AS used for STEM images and elemental mapping shown in Figures 3 and S5.
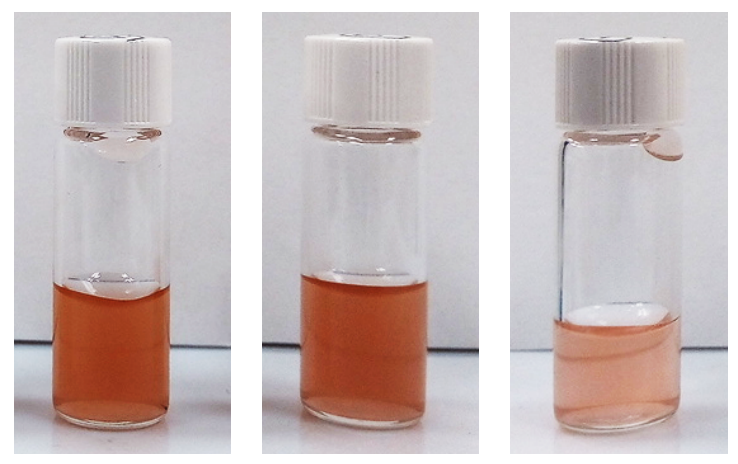

Figure S4. HEM slurries at $\mathrm{pH} 1$ containing left to right: (a) Cat and Ox, (b) Cat and AS, and (c) no Cat or Ox or AS used for STEM images and elemental mapping shown in Figure 4. 
(a) AZTD-Ox-Cat
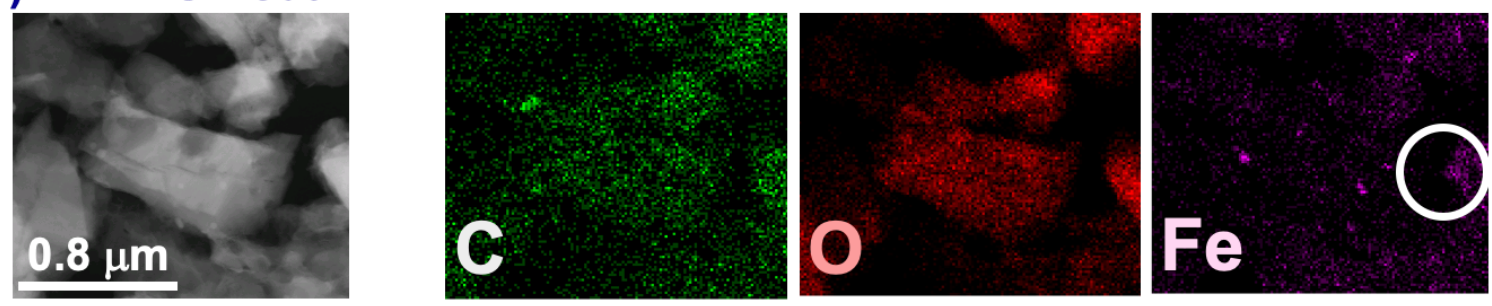

\section{(b) AZTD-AS-Cat}
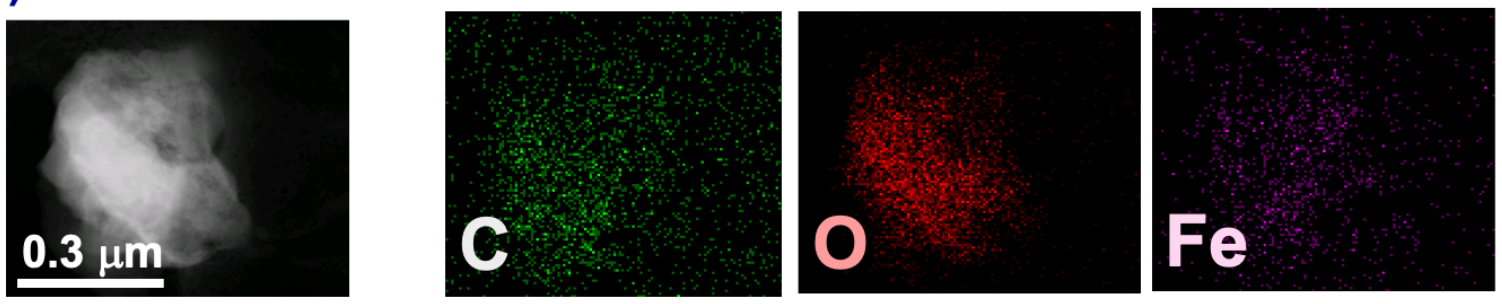

Figure S5. Representative STEM images and elemental mapping of AZTD particles with polycatechol in the presence of oxalate and ammonium sulfate. Slurries used for the images are shown in Figure S3.

\section{(a) AZTD-Ox}

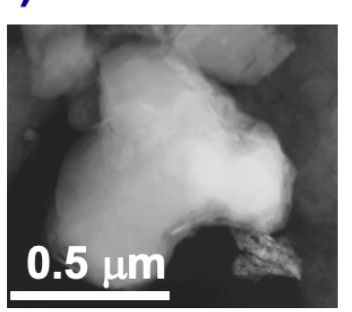

(b) HEM-Ox

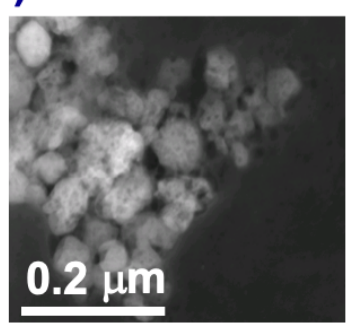

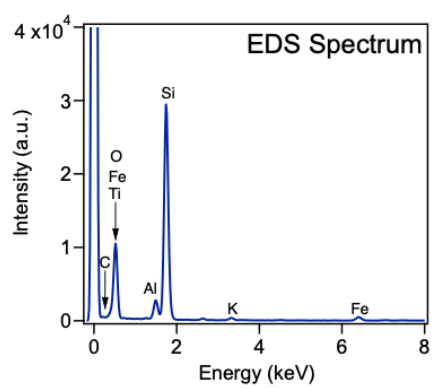

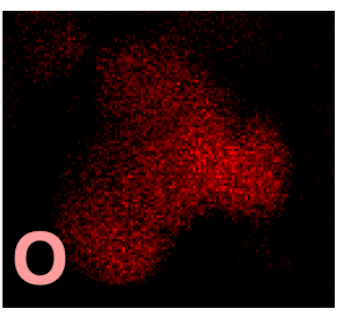

Fe
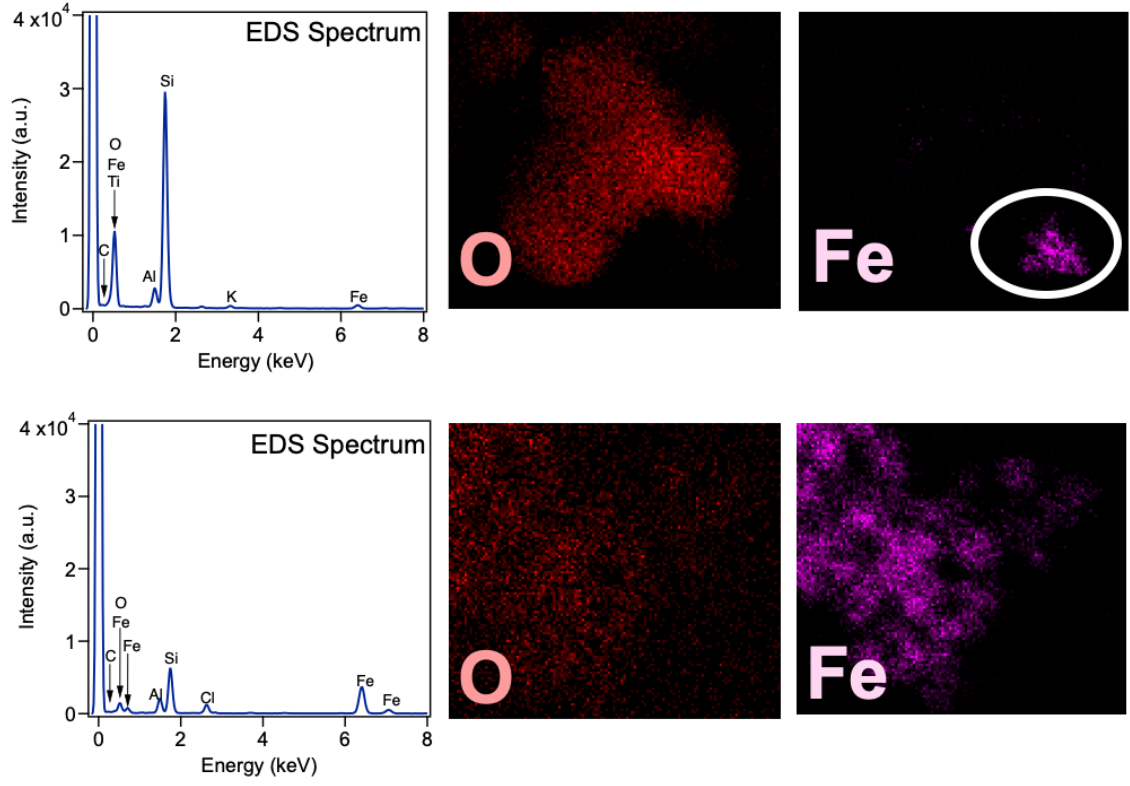

Figure S6. Representative STEM images and EDS spectra of (a) AZTD and (b) HEM particles reacted with oxalate only (no catechol). There is no carbon signal in the EDS spectra. Hence, no elemental map for carbon was generated. 
Table S1: Results of EDS elemental analysis expressed as atomic\% for the STEM images of AZTD and HEM nanoparticles. The x-ray elemental analysis is based on the intensity originating from the Kal shell.

\begin{tabular}{|l|l|l|l|l|}
\hline Sample & Fe_Ka1 & O_Ka1 & C_Ka1 & Total \\
\hline Figure 2a - AZTD-Cat & 3.7 & 91.8 & 4.5 & 100 \\
\hline Figure 2b - AZTD only (control) & 4.5 & 95.5 & - & 100 \\
\hline Figure S5a - AZTD-Ox-Cat & 1.5 & 96.6 & 1.9 & 100 \\
\hline Figure S5b - AZTD-AS-Cat & 1.5 & 96.1 & 2.4 & 100 \\
\hline Figure 3a - HEM-Ox-Cat & 36.6 & 59.3 & 4.1 & 100 \\
\hline Figure 3b - HEM-AS-Cat & 44.6 & 51.2 & 4.2 & 100 \\
\hline Figure 3c - HEM only (control) & 35.4 & 64.6 & - & 100 \\
\hline
\end{tabular}



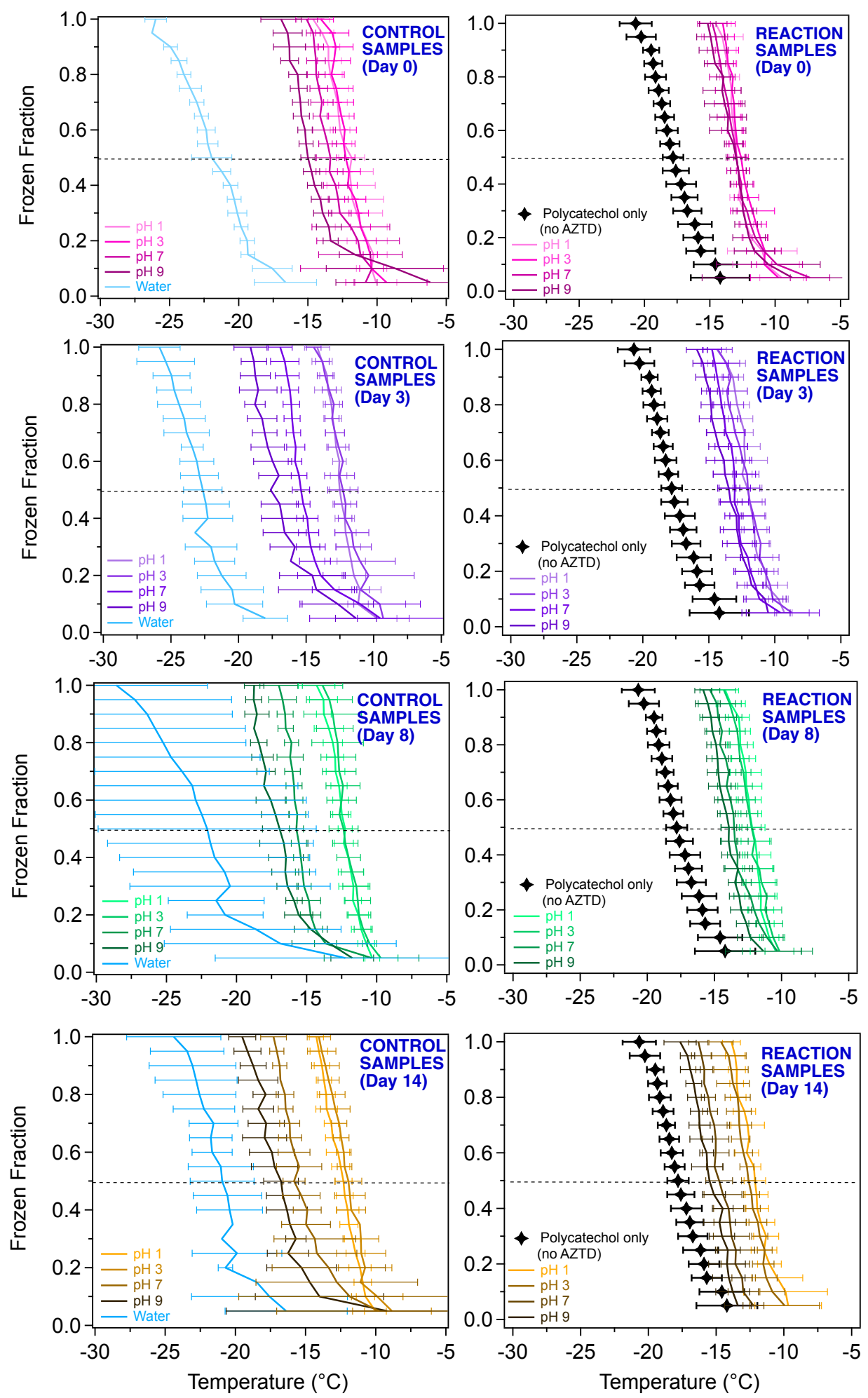

Figure S7: Fraction of droplets frozen containing known concentrations of AZTD particles as a function of $\mathrm{pH}$ and simulated atmospheric aging time. The samples were taken from the vials shown in Figure 1. For comparison, similar data for water droplets and those containing known concentration of polycatechol only (no AZTD) are also shown. The dashed line marks $50 \%$ of the frozen fraction at a given freezing temperature (T50). Error bars in T50 represent propagated $\pm 2 \sigma$. See section 2.5 for surface area of AZTD in these experiments. 


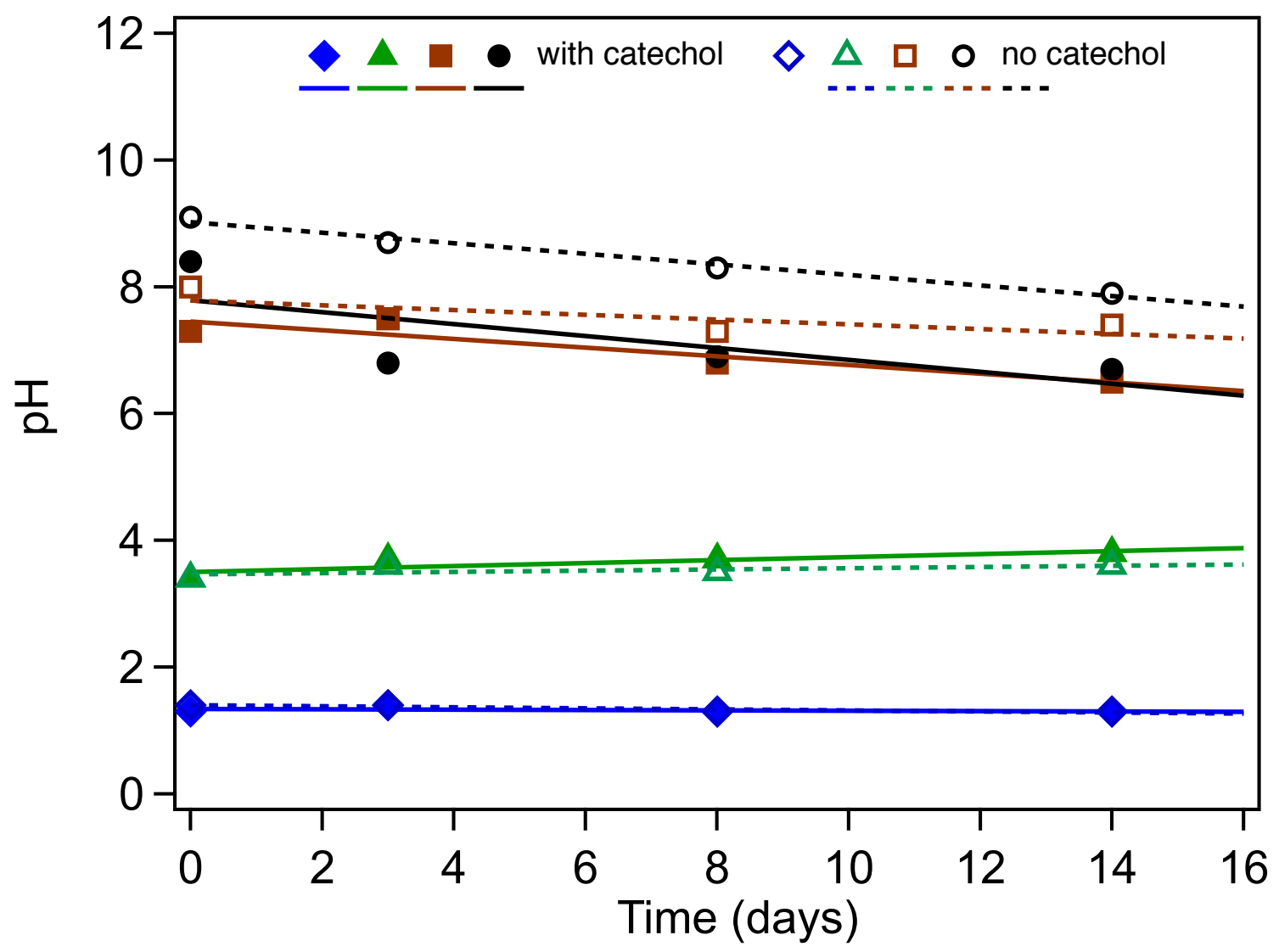

Figure S8: Variation of $\mathrm{pH}$ in the AZTD vials shown in Figure S6 with catechol, and control (no catechol), as a function of simulated atmospheric aging time. 
Table S2: Point of zero charge $\left(\mathrm{pH}_{\mathrm{PZC}}\right)$ of minerals in AZTD

\begin{tabular}{|l|l|l|}
\hline Mineral & PZC & Reference \\
\hline Muscovite & $5.8-6.8$ & 1 \\
\hline Quartz & $<3$ & 2,3 \\
\hline Albite & $<2$ & 4 \\
\hline Kaolinite & $5.5-6$ and $<2$ depending on source & 2 \\
\hline Sanidine & $<1$ & 1 \\
\hline Calcite & $\leq 9.5$ depending on source & 1 \\
\hline
\end{tabular}




\section{References:}

(1) Kosmulski, M., Surface charging and points of zero charge. CRC Press: Boca Raton, FL, 2009; Vol. 145.

(2) Kosmulski, M., pH-dependent surface charging and points of zero charge III. Update. $J$. Coll. Inter. Sci. 2006, 298, 730-741.

(3) Kosmulski, M., Isoelectric points and points of zero charge of metal (hydr)oxides: 50 years after Parks' review. Adv. Coll. Inter. Sci. 2016, 238, 1-61.

(4) Kursun, I., Determination of flocculation and adsorption-desorption characteristics of Nafeldspar concentrate in the presence of different polymers. Physicochem. Probl. Miner.

Process. 2010, 44, 127-142. 